\title{
Making sense of conservation behaviours in Mustang, Nepal
}

\author{
C. S. S. França ${ }^{1}$, E. O. Kyei ${ }^{2}$, G. S. Aragundi ${ }^{1}$ and R. L. Rutt ${ }^{1}$
}

\begin{abstract}
Integrated Conservation and Development Projects (ICDPs) have been undertaken in many countries due to expectations of their supporting both natural resource sustainability and livelihoods. However, they have been challenged by critics over the years, who claim that conservation goals take precedence over local development in practice, thereby worsening the vulnerability of resource-dependent people. Nonetheless, one ICDP implemented in Nepal, the Annapurna Conservation Area Project (ACAP), has been largely regarded by researchers and practitioners as an ICDP success case. Under the authority of a conservation-oriented NGO, ACAP, the ICDP engages local communities participatory for resource management. One community within ACAP has been found to have a substantial timber surplus that satisfies conservation goals, but could also become a sizeable and sustainable source of income for local development. We interrogate the rules and practices of timber management in this community to explore the why behind this practice, discussing how modes of environmental governance aimed at producing behaviors to manage natural resources in particular ways ('environmentalists') feature in the seemingly conservation-oriented de jure rules and de facto practices and in authority relations in and around the community.
\end{abstract}

Keywords : ICDP, conservation, local development, decision-making, Nepal

A lthough Integrated Conservation and Development Projects (ICDPs) have been undertaken worldwide to protect biodiversity while addressing social and economic needs of communities, they have also been subjected to wide critique for their lack of effectiveness in achieving conservationdevelopment win-win scenarios (Bauch et al., 2014 Hughes and Flintan, 2001). For instance, Barrett and Arcese (1995) pointed out that conservation goals often take precedence, and because livelihood needs are not meaningfully addressed, illegal (and often unsustainable) harvesting persists. Berkes et al. (2003) argued that the restrictions established by current conservation methods have deprived the local communities of opportunities necessary for their survival and development. Indeed, ICDPs seem to have an implicit bias toward conservation, given that they typically occur in areas with perceived high levels of biodiversity that is worth preserving for its own sake and/or for tourism. Moreover, the revenue generated by conservation, such as tourism, often serves national development over local development. In other words, local development is rarely a true priority and outcome from ICDPs. Such negative perspectives dominate ICDP-related literature.

Despite the widespread critiques of ICDPs, the Annapurna Conservation Area Project (ACAP) in the highlands of Nepal has been largely described as an example of an ICDP done right (Hughes and Flintan, 2001; Bajracharya et al., 2007; Spiteri and Nepal, 2008; Ojha et al., 2010). Launched in 1986, the ACAP aims to conserve natural resources for the benefit of present and future generations, bring sustainable social and economic development to the local people, and develop tourism in a way that has minimum negative impact on the natural, socio-cultural, and economic environments (NTNC, 2010). Participatory forestry in the

1 University of Copenhagen, Copenhagen, Denmark *All co-authors contributed equally to this article. email: carol.srto@gmail.com

2 Bangor University, Bangor, United Kingdom 
form of local Conservation Area Management Committees (CAMC) has been implemented across much of the ACAP, to enroll residents as custodians of the forests and other natural resources. According to legislation (GoN, 1996), the primary responsibility of the CAMCs (as per Sections 14 and 15) is to prepare and implement a Management Work Plan, which lays out among other details, the rules and restrictions for forest product harvesting.

Recent research carried out in part of the ACAP indicates that a CAMC situated in the lower part of the Mustang district, the so-called 'timber basket' of the region, has established a low quota for timber extraction. Meilby et al., (2014) argue that, within the sustainable limits of the forest, the commercial use of timber could bring approximately three-folds additional income to this community. This would be of particular interest for the communities in this region, where forest income makes up in average $22 \%$ $(12-31 \%)$ of the overall income and is of crucial importance especially to the poorest households (Rayamahji et al., 2012). Although research in the regional context suggests a tendency for top-down technocratic approaches favoring conservation in this area (Meilby et al., 2014, Rutt et al., 2014, Ohja et al., 2014), there is a knowledge gap on "why" local decision-makers would leave commercial timber standing, when it has the potential to increase the incomes of the community through harvest and sale.

Thus, a question persists : what is the rationale behind the decision to keep trees standing? To respond, we refer to existing scholarship describing the production of environmental subjects while examining the status of and rationales behind four main timber rules and practices : how much the communities can/do harvest; what they can harvest; where/who they can sell to; and how much they can sell for. These rules and practices are deemed most significant for conservation and development objectives. Further, we examined perceptions of local development needs and ambitions, including in relation to forest conservation. This study provides a case to the growing body of research looking to understand why decision-makers enact and adopt certain conservative standards under the trade-off conditions of conservation and local development. Furthermore, the rules, practices and their rationales presented here can be helpful to setting up future projects also pursuing the critical dual goals of resource conservation and human wellbeing.

\section{Explaining conservation behaviour : 'environmentalities'}

A dominant perspective to explain why different actors practice resource conservation behaviour stems from the Foucauldian notion of governmentality (the cultivation of selfregulation in line with the interests of a governing power), in relation to environmental governance and behaviours. Called 'environmentality', this perspective originally examined shifts in belief systems toward a supposed intrinsic valuation of natural resources. Environmentalities are poststructural conceptualizations of modes of environmental governance (Bluwstein, 2017) aimed at the production of behaviours that protect and manage the material environment in certain ways (Fletcher, 2010; Agrawal, 2005). Agrawal (2005) described how "environmental subjects" are created that care about resource conservation. He found firstly, that individuals' beliefs about forests were found to vary not because of socioeconomic aspects, but because of people's involvement in regulatory practices (Agrawal, 2005). Through participation in forest protection, the values held by the local "environmental subjects" were reshaped to converge with those of the ruling power, which in this case largely favoured resource conservation.

In more recent work on this concept, scholars have extended the notion to describe multiple types of environmentalities. Fletcher, (2010) draws from the extensive work of Foucault to elaborate four variations : disciplinary, neoliberal, sovereign, and truth environmentalities. Disciplinary environmentality is an authoritative technique of government through the invocation of an environmental morality (largely the version put forth by Agrawal). Neoliberal environmentality is implemented through economic incentives that assume and cultivate self-interest and competition, and steeringbehaviour towards productive ends. Sovereign environmentality invokes the power of the state authorities, typically manifesting through other environmentality projects and often visible in the conservation sector through command and control, 'fences and fines' type 
approaches. Finally, truth environmentality is employed by people and institutions to promote supposed universal ideas (e. g. wilderness, nature, indigeneity) or depict an essentialist connection, such as between 'indigenous' or 'local' people and 'nature' (Bluwstein, 2017). These 'truths' can serve diverse agendas, from empowerment of typically vulnerable groups to conservation ambitions.

Fletcher, (2010) describes how these different forms of environmental subject-making occasionally overlap. He provides an example : "neoliberal governmentality could be seen as reliant upon certain disciplinary techniques to facilitate its operation. That is, disciplinary governmentality would be necessary to construct the rational actors upon which neoliberal governmentality would then operate". He also notes that different governmentalities may also conflict, constituting "the terrain of political debate" and "leading to debate concerning the proper approach to governance within a given situation". While the entanglement of and conflict amongst environmentalities is of great interest, we focus mainly on utilizing these concepts as co-existent explanatory tools to better understand the rationales at work in relation to the timber rules and practices in this context. This unfolds in the later discussion section.

\section{Materials and methods Study site}

Our study site is located in the Mustang District of highland Nepal. It encompasses multiple villages totaling almost $80 \mathrm{~km}^{2}$, with around 1000 inhabitants across approximately 150 households, that largely engage in agriculture as the main income source (CBS, 2011, Larsen et al., 2014). Locals depend on firewood for subsistence needs and timber as a source of income (Larsen et al., 2014). Tourism is an increasingly viable livelihood activity for people in the region (Urothody and Larsen, 2010).

The ACAP is managed by the Nepali NGO National Trust for Nature Conservation (NTNC), which was granted temporary management authority under the supervision of the Department of National Parks and Wildlife Conservation, within the Ministry of Forest and Soil Conservation. The NTNC officials ("ACAP officers'), i.e. a Chief Conservation Officer and technical support staff, work with and provide support and oversight for local Conservation Area Management Committees (CAMC). The CAMC members consist of the Chairperson of the local government body (called Village Development Committee (VDC), one internally nominated representative from each VDC sub-divisions (called wards), and five persons nominated by the ACAP Chief Conservation Officer from among the local users - for a total of 11 members in the CAMC in our site. Members of the CAMC selfselect their leadership (Chairperson, Secretary, etc.). Forest Management Sub-committees (FMSC) are formed to address ward-based management tasks such as the evaluation of timber requested by households (Larsen et al. 2014). ACAP officers also frequently take part in the CAMC meetings.

\section{Data collection}

The field research occurred over two weeks in early 2016. Data was obtained through several methods : (i) literature review, (ii) semi-structured individual and group interviews, with nine CAMC and subcommittee members (many of whom also sit on the main CAMC), with three ACAP officers (in one group interview), and informally with three Nepali forestry scholars with substantial knowledge of this CAMC - making a total of 11 interviews, and (iii) data extraction from the CAMC operational plan (2009), timber transaction records, and meetings minutes. Unofficial discussions with approximately ten residents that do not hold CAMC positions and observation of conditions in the villages and forest were used for triangulation. Interviews were carried out simultaneously in English and Nepali with the aid of a translator acquainted to the local context. All interviews were recorded and transcripted. Documents in Nepali were translated. Interview transcripts and supporting documents were analysed by following an interpretative approach (Elliott and Timulak, 2005). Quantitative data on timber harvest records, income, price, and sale were analysed using Excel.

\section{Results and discussion Results}

The following section presents four main timber rules (de jure) and practices (de facto), namely how much, what, where, and for how much, as well as perceptions on local development needs and ambitions. 


\section{How much can/do they harvest ?}

The CAMC management operational plan provides an upper limit for timber extraction of $5000 \mathrm{ft}^{3}$ $\left(141.58 \mathrm{~m}^{3}\right)$ for use by insiders and $3500 \mathrm{ft}^{3}(99$. $11 \mathrm{~m}^{3}$ ) for use by outsiders, making a total of approximately $8500 \mathrm{ft}^{3}\left(240.69 \mathrm{~m}^{3}\right)$ per annum (Rutt et al., 2014). Timber transaction records show the total harvest between 2008/9 to 2015/16 (in accordance with the Nepali calendar; Fig. 1). The amount consists of extraction for both 'insiders', or those from within the CAMC territory, as well as 'outsiders', who live within the same Mustang district and within the overall ACAP. As is shown in Figure 1, the total harvest has exceeded the limit stated in the plan. In fact, the CAMC members described the practice of an "extraction system" of a 60/40 ratio using dead or dying wood, whereby $60 \%$ of any dead and dying wood can be harvested, with $40 \%$ left in the forest to support biodiversity conservation and soil fertility as well as to retain some usable wood for the (near) future, as needed. Interviews revealed what appears to be a heavy reliance on the ACAP technicians to give approval regarding how much of the available timber actually constitutes the harvestable 60 (or 80) percent. For example, one sub-committee member explained : "In the event of a storm, for instance, we just call the ACAP officials and they do the monitoring with special method and we harvest according to the forest technicians' estimates". In times of crisis, such as heavy storms, forest fires, and earthquakes - events which both make timber available for extraction but also increase demand for repair of buildings, fences, and other infrastructure - the system changes to 80/20. As mentioned by interviewees, peak times visible in the graph coincide with incidences of such emergencies, most recently the 2015 earthquake.

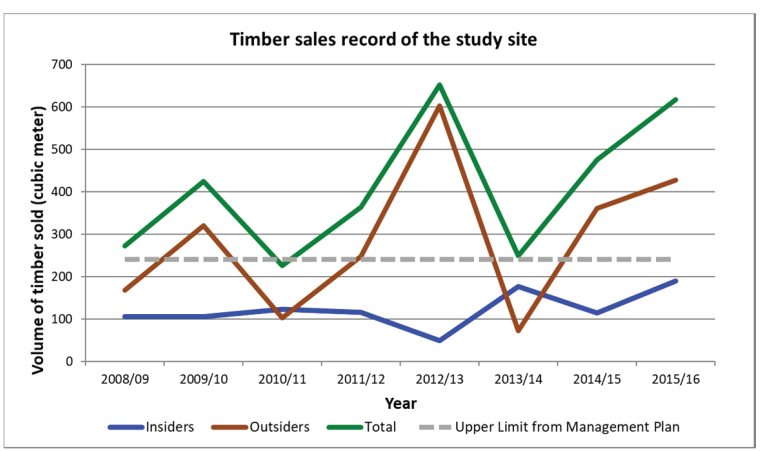

Fig. 1: Trend of Timber extraction (from sales records) of the CAMC, 2008/9 - 2015/16
The years on the graph reflect the Nepali calendar. For instance, the year 2008/09 on the graph reflects the Nepali year of 2065, which begins in April/ May 2008 and ends on March/April 2009 when translated into the English calendar. This explains why the years on the graph overlap. Insiders are consumers of timber within the CAMC. Outsiders are consumers of timber outside the CAMC, but within the Mustang district of which the CAMC is a part. The "Upper Limit" is the total amount of timber that can be extracted for use as stipulated in the sites forest management plan.

Yet, forest inventory data from Meilby et al. (2014) based on estimates of annual tree volume increments and extractions from 122 permanent plots in the High mountain site (of which the CAMC territory is a part), over a period of five years (2005-2010), suggest that the actual annual harvest of timber in the CAMC area is lower than what the sustainable harvest levels should be for their forest. Specifically, they state that about $4192 \mathrm{~m}^{3} \mathrm{yr}^{-1}$ (i.e. $80 \%$ of the estimated 5240 $\mathrm{m}^{3} \mathrm{yr}^{-1}$ mean annual increment) is the sustainable harvest level for the High mountain forest.

\section{What can they harvest ?}

To meet local timber needs, the operational management plan (2009) states permitted species for harvest and sale include Pine (Pinus wallichiana), Dhupi (Cupressus torulosa) and Kisin (Tsuga dumosa) and "the dried and felled tree should be provided by the committee". The plan prioritizes "dried and felled tree", which is notable given the higher economic and use value of green (live) timber. The plan continues, "In case of green or standing tree, the girth should exceed $5 \mathrm{ft}$ ". However, trees with a girth over $5 \mathrm{ft}$ are uncommon in this forest. Further, as elaborated by inter viewers, for the previous three years, the felling of green trees had been effectively banned. Exceptions occurred only under very special conditions - such as when dead or dying wood is in short supply and an urgent (non-commercial) need emerges - and only in "very limited" quantity.

The reasons given to support the ban included a preoccupation with the capability of the forest to provide for future generations. One committee member explained : "green tree felling [happened] only in the beginning [when 
the CAMC was formed] but when we became more aware of conservation we stopped doing that". Some raised the point that the forest litter provided by green trees is an essential input (e.g., manure) to local agriculture, especially since they do not use commercial fertilizer. Others explained that allowing for green timber harvest will likely incentivise people to harvest green timber close to the villages and to the most accessible places and trails, instead of going far inside into the forest to harvest available dead and dying wood. If this happens, it may reduce the aesthetic or touristic value along for instance trails, and this they believe can negatively affect the emerging ecotourism in the area.

Another driver behind the ban appeared to be pressure from the ACAP. A general consensus seems to have been established between the CAMC and ACAP officials to refrain from using green trees for the foreseeable future. When pushed in interview, a few CAMC officials admitted that "from time to time we have raised our concern and interest in using green trees for harvesting but the ACAP does not approve, they tell us it's not good". In a separate interview, The ACAP officials acknowledged, "There are a few that are not happy."Yet they justified their position by explaining, "The district has areas with very little trees, so all have to conserve. Yes, we bind [this area] to rules, like other areas. We have our directives, we must follow, for conservation. The forest is also home to other biodiversity. We can not forget this."

At the same time, a visit to one of the arguably most elite members of the community (owning comparatively large assets) and of the CAMC (having held several executive positions), admitted during a field visit that green trees are "occasionally" used to construct fencing on his private property (with non-timber species used for fencing, and timber species for poles). $\mathrm{He}$ acknowledged this was officially against the rules, but justified it by its limited extent. During another field visit with a small group of the CAMC members from ward level (who by appearances were significantly less wealthy), fervently expressed the view that a green tree ban was absolutely essential for the wellbeing of the resource. When pushed to consider circumstances under which it could be appropriate, e. g. if they learned that they had sufficiently abundant resources, they nearly refused to hear the arguments, taking a firm stand that harvesting green trees is not a possible option for them. This dissonance we observed in beliefs and practice across the CAMC members is considered in the coming discussion.

\section{To who/ where can they sell ?}

In relation to timber sale, the Management Operational Plan (2009) draws from the Conservation Area Management Rules of 1996, which state that the CAMCs are allowed to sell timber only to areas within the Mustang district of the ACAP. A CAMC respondent explained that the restrictions stemmed from the substantial dependency of those from barer parts of the district, positioning them as the district's 'timber basket'. Timber sale records (Fig. 1) show an increase in the amount of timber traded over the years, which reflects an increase in timber demand over the years with more demand from buyers outside this CAMC. The district's growing furniture industry is the principal buyer. Some respondents suggested that if the market was not restricted, sales would likely expand to beyond the district, possibly at higher prices.

\section{How much can they sell for ?}

Current government regulation stipulates that timber may not be sold at less than NPR 100 (USD 0. 96) per $\mathrm{ft}^{3}$ (i.e. about NPR, 3,531 or USD 33.15 , per $\mathrm{m}^{3}$ ), for outsiders. This CAMC sells timber at NPR 150 (USD 1.45) per $\mathrm{ft}^{3}$ (i. e. USD 51. 20 per $\mathrm{m}^{3}$ ) to outsiders; insiders pay a highly subsidized price of NPR 10 (USD 0. 10) per $\mathrm{ft}^{3}(\mathrm{i}$. e. USD 3.53 per $\mathrm{m}^{3}$ ). Timber prices and income have increased over the years (Fig. 2), revealing an awareness and interest in maximizing income potential that was confirmed in interview. Timber prices in some neighbouring CAMCs are higher, at NPR 200 (USD 1.94) per $\mathrm{ft}^{3}$ (i.e. USD 68.51 per $\left.\mathrm{m}^{3}\right)$. The CAMC respondents explained that while they are actively considering a price increase, current prices reflect careful rationales. Low insiders' prices are believed to incentivize forest protection by the local users. The CAMC officials also justified their relatively lower prices for outsiders (compared to neighbouring CAMCs) by referring to their comparatively worse roads and severe topography that is more susceptible to flooding. Poorer access increases the price 
for buyers, who bear the cost of harvesting and transport themselves. Therefore, selling timber at a price lower than neighbours enables them to be competitive.

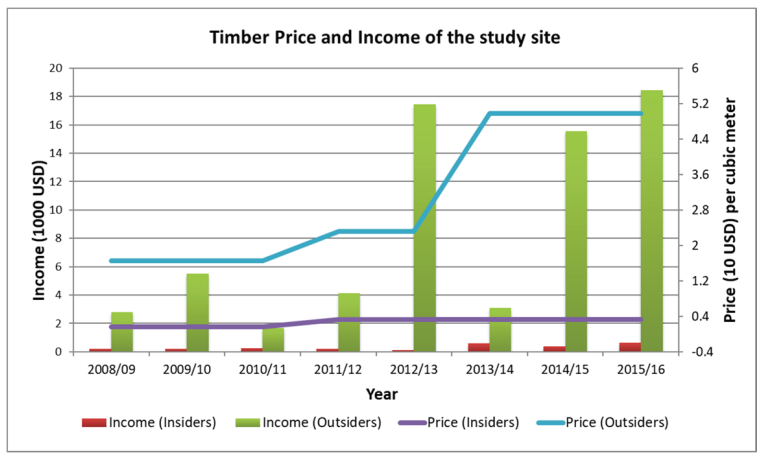

Fig. 2: Trend of timber income and price of the study site from 2008/9-2015/16

The years on the graph reflect the Nepali calendar. For instance, the year 2008/09 on the graph reflect the Nepali year of 2065, which begins in April/ May 2008 and ends on March/April 2009 when translated into the English calendar. This explains why the years on the graph overlap. Insiders are consumers of timber within the CAMC. Outsiders are consumers of timber outside the CAMC, but within the Mustang district of which the CAMC is a part.

\section{What are local development needs and ambitions?}

Respondents were questioned on their perceptions of local development needs, ambitions, and their priorities in relation to development and conservation. In terms of need, respondents referred to small industry development, better employment opportunities, and general education, mentioning the heavy reliance on "just agriculture" in problematic terms. Several expressed interest in more ecotourism in their area (also referred to above). It is also notable that one of the CAMC sub-committees is explicitly dedicated to 'tourism'. The same respondent described shifts in the community toward more "welcoming" attitudes to visitors as compared to the past. Another described the role for forest product sales, "The funds that we are generating helps the people in building some cottage industries and the harvesting also provides some employment for the youth in the area. So yes, it's helping a lot in local development." But as many respondents, this one quickly expressed concern for conservation goals : "The demand for timber is high. We fear we may not be able to meet the demand in a sustainable way. "A few respondents described some dissatisfaction with the distribution of the CAMC funds to local development and livelihood enhancement vs. conservation. Two for instance referred to a lack of resource allocation to protect agricultural areas from wildlife disturbance. Yet overall, conservation was largely a part of any response to inquiries into local development - as if the two are for the most part inseparable.

From the perspective of the ACAP, tourism has potential for this CAMC, but it is something for 'the future'. The ACAP officials also acknowledged the importance of including development goals particularly for community motivation to conserve. The ACAP officer clarified their first priority: "As a conservationist, I must say we have to prioritize conservation". Overall it appears The ACAP is both assisting tourism development and local development, but also holding it back when it appears to be in odds with conservation priorities.

\section{Discussion}

In his work on the concept of 'environmentality', Agrawal (2005) describes a process by which people come to see themselves as defenders of the environment because of their involvement in regulatory practices. While we were unable to dig deeply into behaviour and value changes in practice across the community over time, many of the interview responses seem to align with the changes described by Agrawal (2005), corroborating with the idea that local decision-makers have become environmental subjects from their interaction with the regulatory system promoted through participatory forestry and championed by the ACAP officials. The CAMC members described a generally heavy reliance on the ACAP officials for practical issues (e. g. the presence of the ACAP officials is described as necessary to legitimate the CAMC decisions on which trees and how much they can harvest), which over time likely encroached even into the value system that the CAMC members promote in their community. Some described, "ACAP has had a very big impact on mindsets of people regarding conservation". We learned that the ACAP officials take an active part in the CAMC meetings and during any key 
decisions. The ACAP officials also acknowledged the influential role that they have on the committee members, which have led to substantial changes in community forest management practices. One ACAP conservation officer described the numerous awareness and conservation programmes they hold (also frequently referred to by the CAMC members), "to sensitize the local people of the importance of conservation", noting, "We made them follow it strictly."

This relationship between ACAP officers and CAMC officials appears to be a manifestation of mutually reinforcing disciplinary, truth, and sovereign (state-authority driven) environmentalities (following Fletcher, 2010), through ACAP's frequent presence and heavy hand in forest management as well as the emphasis on conservation as a primary value, where development goals are instrumentalized to motivate conservation behaviors (e.g. tourism only as it aligns with conservation). A conservation ethos certainly seems to be predominant in most de jure rules and de facto practices. In reaction to limitations on how much they can and do harvest, to what they can harvest (the ban on green timber), and where, the forest inventory data from Meilby et al., (2014) imply that increasing harvest to maximum sustainable levels would allow for a tripling of forest income for the CAMC. The conclusions of Meilby et al. 's work in 2014 were reiterated during our own field work by a team of international foresters conducting technical research in the same area. After examining multiple forest plots (though less extensively than Meilby et al.) this group also called for the harvesting of green trees to improve forest condition and particularly, to allow for increased timber values to develop - if desired Community sales records demonstrate income from timber sales is increasing (Fig. 2). Since timber prices have only risen marginally, this implies that the increase in income may be a result of increase in the number of customers or increases in the average transaction size. This corresponds to the CAMCs claim that the demand for timber in the region is very high. This reinforces the claim of Meilby et al. (2014) that incomes would rise if current harvest levels are increased, given the ongoing high demand for timber in the region. The demand for timber in Nepal is certainly high. The Himalayan Times (2016) reported that almost 30 million cubic feet of timber were imported from e. g. Malaysia, Indonesia, and African countries, to fill the timber supply gap left as a result of strict regulations against extraction of timber in Nepali forests. Prices of timber also appear higher outside the Mustang district. For instance, the average price per cubic feet of the same timber produced in this CAMC, Pinus wallichiana, on the Nepali market was reported at around NPR 900 (USD 8.73) (Housing Nepal, 2010), while the CAMC sold to outsiders (but within the district) at just NPR 70 (USD 0.68). The high demand for timber and better prices outside the Mustang district means that more income could be generated by expanding the market beyond the district. Therefore, a decision to leave timber in the forest suggests an inclination towards conservation over local development.

Yet while a conservation ethos manifests in some of the explanations of rules by the CAMC representatives, they are also concerned with more economic-oriented values of standing forests, suggesting the growth of a neoliberal environmentality that, for now, aligns with the overarching conservation agenda. For instance, litter from green trees provides an important source of mulch for their agricultural production - a main source of income for most - as opposed to purchasing expensive chemical fertilizer. Furthermore, the CAMC representatives' interest in ecotourism also indicates that the environmental income from such activities in the area is more desirable than potential income from harvesting and sale of the green trees. One sub-committee member (with an advantageous location for benefiting from tourism) stated "a lot of the revenue is being produced by the tourism, thousands of rupees" - despite that this has not yet really manifested in their area. Regarding timber sale price, the CAMC seems to be operating from a profit-maximizing rationale in that timber prices are set lower than neighbouring areas, to make up for their infrastructural and other accessibility challenges. We interpret their pricing decision as a thoughtful strategy to both conserve forests and support local development. Keeping price low for insiders is expected to induce resource conservation, which may be evident in how strictly the community seems to follow conservation rules, the low occurrence of illegal logging, and the abundance of timber resources that meet their needs. On the other hand, low prices of timber for insiders ensure that locals have access to cheap timber and fuelwood, which can induce savings on incomes. Such savings can be channeled into provision of other livelihood or local development needs, such as to support the education of children or purchase other household items. Of course, low 
'internal' timber prices have been found to benefit the wealthier community members more, as they are often best enabled to channel cheap timber into infrastructure that allows them to benefit from, e.g., tourism opportunities (Lund et al., 2014). Poorer people, without the capital needed to take advantage, simply lose due to the lost revenue from sales that might have benefited everyone. Overall, the explanations and practices of the CAMC respondents (notably CAMC leadership) seem to echo Fletcher (2010) and others (Bluwstein, 2017) depictions of a neoliberal environmentality that prioritizes conservation for positive economic incentives - with a particular bias in favour of already better off residents. We do wonder if this form of 'environmentality'with its emphasis on profit, may come to undermine the other forms so carefully cultivated by conservation authorities.

The practice of using small green trees for fencing poles by the CAMC elites (shunned officially and unlikely to be practiced by regular users), combined with the insistence of lower-ranking CAMC members (those from the ward level that are poorer and that do not hold executive positions within the CAMC) of the importance of protecting valuable green trees, also makes us also wonder if a sort of 'trickle-down' environmentality might be occurring. By this, we mean that whereas the CAMC elites, constituted by aspects of wealth/assets, education, caste, etc., are most likely to have participated in ACAP awareness and conservation programmes, we imagine a sort of 'environmentality' transfer taking place down to socially lower ranking community members. These members receive the knowledge of conservation practice and ethos from their authoritative/social 'superiors' through the regular practice of the CAMC meetings and responsibilities. Environmental 'subjecthood' is not necessarily a permanent condition, and the concern for the environment as pushed by the ACAP officials may now be pushed upon the lower ranking officials at sub-committee level, to encourage their conformity to rules while freeing up elites to push the boundaries of legality so to speak for their own benefit (which at this limited scale is unlikely to cause substantial forest damage). In other words, if community elites can successfully (through indoctrination into a conservation morality), produce overall conformity to rules, then their occasional breaking of rules is unlikely to be seen as problematic by those to whom they are ultimately accountable to - the
ACAP officials. This raises questions as to the effectiveness and durability of 'environmentalities' and in this case, particularly disciplinary and truth environmentalities that are based particularly on morality/belief systems. In fact, it is precisely the upward pathways of accountability that have complicated participatory resource management in practice in other parts of Nepal, whereby relations of patronage amongst community elites and forest officers come to outweigh the accountability of community group executives to regular and less powerful users (Malla, 2001). We suppose that if we were informed about the practice of green tree harvest for the use of elites within a relatively short field visit, other similar practices would likely come to light over time. As such, this context may contribute to increasing disparity within the community rather than comprehensive community development. The nature of environmentality transfer downward through social strata, as well as the effectiveness and durability of various environmentalities over time, are research arenas we hope more researchers will explore further, particularly through more in-depth research than we were able to conduct for this study.

\section{Conclusion}

While at first glance some rules and practices appear to favour conservation due to their strictness in restricting the harvesting or commercialization of standing timber, a second look at the rationales behind those rules and some practices in the study area tell a more nuanced story. Overall it appears that the interests of the locals and the authorities converge, leading to resource conservation behaviours and outcomes, and there appear to be multiple environmentalities at work in the community - not purely the disciplinary and other environmentalities that imply the uptake of a morality of the intrinsic value of forests, but also a growing neoliberal environmentality oriented towards the economic potential of resource conservation. Further, we believe that there is a 'trickle-down' effect occurring in the study area, where disciplinary, sovereign, and truth environmentalities that promote both certain value systems (conservation for conservation's sake), and the maintenance of systems of authority, first occurs through an indoctrination of community leaders via ACAP trainings (and frequent engagement in decision making spaces). Community leaders eventually transfer such environmental subject- 
hood to lower ranking community members, as they simultaneously take advantage of their own authority to push boundaries of legality. This we believe may have led to a broader community of "environmental subjects" - but we question whether it is effective and durable in terms of conservation goals. We also question durability of the conservation ethos under a growing (if slowly) neoliberal environmentality prioritizing profit.

Future research could further investigate how exactly multiple environmentalities are taken up, maintained or contested, undermine one another and also travel among different types of people over time. Research on participatory forestry across Nepal has also indicated a persistent and widespread context of elite capture in decision-making and in the distribution of benefits. Thus, interrogating differences in the impacts of decisions across the communities also appears pertinent.

\section{Acknowledgements}

All co-authors contributed equally to this article. This study was developed in connection with the M. Sc. Sustainable Tropical Forestry program organized by a consortium of five European Universities - Bangor University, UK, University of Copenhagen, Denmark, Dresden University of Technology, Germany, Agro Paris Tech, France, and University of Padova, Italy - and benefited from the Erasmus Mundus Scholarship offered to students by the European Commission. The authors are deeply grateful to the CAMC members, ACAP officers, and forestry scholars for their time and valuable insights. We would like to thanks Bidhan Adhikary and Ashmi Ramachandran for their various crucial contributions to this research as well as to Muna Sharma and Bidhya Sharma for their invaluable support in the field and for translating the interviews. We are also grateful to Henrik Meilby for his generous feedback on this manuscript. We thank the Institute of Forestry Pokhara for the organization of fieldwork logistics.

\section{References}

Agrawal, A. 2005. Environmentality : technologies of government and the making of subjects. Duke University Press, Durham, USA. 161-190.
Bajracharya, S. B., Gurung, G. B. and Basnet, K. 2007. Learning from Community Participation in Conservation Area Management. Journal of Forest and Livelihood 6 (2) : 54-66.

Barrett, C. B. and Arcese, P. 1995. Are Integrated Conservation-Development Projects (ICDP's) Sustainable? On the Conservation of Large Mammals in Sub-Saharan Africa. World Development 23 (7) :1073-1084.

Bauch, S. C., Sills, E. O., and Pattanayak, S. K. 2014. Have We Managed to Integrate Conservation and Development? ICDP Impacts in the Brazilian Amazon. World Development $64\left(\mathrm{~S}_{1}\right)$ : 135-148.

Berkes, F., Colding, J. and Folke, C. 2003. Navigating social-ecological systems : Building resilience for complexity and change. Cambridge University Press, Cambridge, UK.

Bluwstein J. 2017. Creating ecotourism territories : Environmentalities in Tanzania's community-based conservation. Geoforum $83: 101-113$.

CBS, 2011. National Population and Housing Census. Central Bureau of Statistics (CBS), Kathmandu, Nepal.

Elliott, R. and Timulak, L. 2005. Descriptive and interpretive approaches to qualitative research. In : A handbook of research methods for clinical and health psychology (eds) Miles, J. and Gilbert, P. A, Oxford University Press, London, UK, 147-157.

Fletcher, R. 2010. Neoliberal environmentality : towards a poststructuralist political ecology of the conservation debate. Conserv. Soc. 8 (3) : 171-181.

GoN. 1996. ConservationArea ManagementRegulation, 2053. 1996. English Version. Government of Nepal (GoN), Kathmandu, Nepal.

Himalayan Times. 2016. Over 80 percent of timber imported from foreign countries. June 20, 2016. 
Housing Nepal. 2010. Prices of plywood (per sq. ft) and wood species (per cubic feet). (Online). Available at : http ://www. housingnepal. com/articles/display/prices-of-ply-woodperq-ft-and-wood-species-per-cubic-feet Accessed 31-01-18.

Hughes, R. and Flintan, F. 2001. Integrating conservation and development experience : A review and bibliography of the ICDP Literature. International Institute for Environment and Development, London, UK.

Larsen, H. O., Rayamajhi, S., Chhetri, B. B. K., Charlery, L. C., Gautam, N., Khadka, N., Puri, L., Rutt, R. L., Shivatoki, T., Thorsten, R. S., and Walelign, S. Z. 2014. The role of environmental incomes in rural Nepalese livelihoods 2005-2012 : contextual information. Frederiksberg : Department of Food and Resource Economics, University of Copenhagen. IFRO Documentation 2014 14.

Lund, J. F., Baral, K., Bhandari, N. S., Chhetri, B. B. K., Larsen, H. O., Nielsen, Ø. J., Puri, L., Rutt, R. L. and Treue, T. 2014. Who benefits from taxation of forest products in Nepal's community forests? Forest Policy and Economics 38 (1) : 119-125.

Malla, Y. B. 2001. Changing Policies and the Persistence of Patron-Client Relations in Nepal : Stakeholders' Responses to Changes in Forest Policies. Environmental History 6 (2) : 287-307.

Meilby, H., Smith-Hall, C., Byg, A., Larsen, H. O., Nielsen, Ø. J., Puri, L., and Rayamajhi, S. 2014. Are Forest Incomes Sustainable? Firewood and Timber Extraction and Productivity in Community Managed Forests in Nepal. World Development $64\left(\mathrm{~S}_{1}\right)$ : 113-124.

NTNC 2010. National Trust for Nature Conservation Website. http ://www. ntnc. org. np/project/annapurna-conservationarea-project. Accessed 6-11-17.
Ojha, A. P., Koh, K. L., and Chun., J. 2010. Integrated conservation and development program approach in protected area management : Case study of annapurna conservation area project in Nepal. 207228. In : Lye, L. H., Ofori, G., Choo, M. L., Savage, V. R., Yen-Peng, T. Sustainability Matters : Environmental Management in Asia. World Scientific, Singapore.

Ojha, H. R., Banjade, M. R., Sunam, R. K., Bhattarai, B., Jana, S., Goutam, K. R., and Dhungana, S. 2014. Can authority change through deliberative politics? Lessons from the four decades of participatory forest policy reform in Nepal. Forest Policy and Economics 46 : 1-9.

Rayamajhi, S., Smith-Hall, C., and Helles, F. 2012. Empirical evidence of the economic importance of Central Himalayan forests to rural households. Forest Policy and Economics 20 : 25-35.

Rutt, R. L., Chhetri, B. B. K., Pokharel, R., Rayamajhi, S., TiwariI, K., and Treue, T. 2014. The scientific framing of forestry decentralization in Nepal. Forest Policy and Economics 60 : 50-61.

Spiteri, A. and Nepal, S. K. 2008. Evaluating local benefits from conservation in Nepal's Annapurna Conservation Area. Environmental Management 42 (3) : 391401.

Urothody, A. A., and Larsen, H. O., 2010. Measuring climate change vulnerability : a comparison of two indexes. BankoJanakari 20 (1) : 9-16. 